\title{
Modelos diaspóricos y paradiplomacia: los casos irlandés y vasco en Argentina
}

María Eugenia Cruset

Universidad Nacional de La Plata. Universidad Católica de La Plata (Argentina)

\section{Introducción}

A modo de introducción, este trabajo pretende mostrar de forma comparativa los procesos migratorios de vascos e irlandeses en la Argentina, su grado de asimilación, su vinculación con las Madre Patrias y la conexión entre ambas. Utilizando la categoría de "diáspora” se analiza su acción política, social y cultural, y reflexionamos sobre la posibilidad de considerar esta actividad como "paradiplomacia".

Este es una investigación de carácter histórico que utiliza fuentes emanadas de los dos grupos migrantes y de la sociedad de acogida tanto como la de origen. Sin embargo, trataremos de analizarlas usando marcos teóricos de otras disciplinas como la antropología, las Relaciones Internacionales y las Ciencias Políticas, entre otras.

\section{Migración y transnacionalismo}

Hasta hace poco el fenómeno migratorio no era estudiado en su aspecto global, esto es, como un proceso. Esto sucedía porque se circunscribía 
el análisis a los marcos de los Estado-nación en su papel de "Sociedades receptoras", destacando conceptos como "asimilación efectiva" o "integración nacional". En particular la antropología y la sociología, pero también en algún grado la ciencia histórica, presuponían que la asimilación a la sociedad de acogida implicaba necesariamente una ruptura con la identidad de origen, al menos con lo que se refiere a lo político. Esto se acentuaba en contextos históricos donde las dificultades del traslado convertían en casi unidireccional su viaje.

En este sentido hay que señalar que los movimientos migratorios fueron estudiados desde fines del siglo XIX tratando de entender sus causas y motivaciones; es decir: ¿qué hacía que una persona quisiera dejar su lugar de origen y las razones de elección de uno nuevo? Así se crearon dos corrientes: la "pesimista" y la "optimista". La primera de ellas decía que emigraban porque debían escapar de la "miseria”, mientras la segunda hacía referencia a la búsqueda de "mejor fortuna" por parte de los emigrantes. Esto era una diferenciación ideológica entre los que lo veían como un desarrollo positivo (los partidarios del capitalismo) y los que lo rechazaban como sus efectos no deseados o negativos. Entre los primeros se encuentran los economistas liberales y entre los segundos una gran cantidad de distintas corrientes que iban desde los socialistas, pasando por los nacionalistas (que veían como las energías jóvenes se iban de su propia tierra) o los católicos tradicionalistas que veían alterar el orden existente y la posible pérdida de la fe.

Estos argumentos se mantuvieron con las ideas teóricas del Pull/ Push (atracción/expulsión), donde los pesimistas enfatizaban la expulsión y los optimistas la atracción. Los mejores casos para los pesimistas son tres: España, Francia e Irlanda, este último casi emblemático (Devoto, 2009).

Se puede decir que esta visión se mantuvo hasta bien entrada la década de los años ochenta, cuando los estudios migratorios comenzaron a aplicar una mirada simultánea en origen y destino que permitió formular nuevas preguntas al fenómeno migratorio, al incorporar las relaciones, vínculos y prácticas que se inscriben más allá del territorio nacional. Son trabajos que exploran un análisis del fenómeno migratorio, dando cuenta de las prácticas que los emigrantes despliegan, no 
solo en los países de destino sino en cuanto a las relaciones (familiares, culturales, económicas, políticas, religiosas) que siguen manteniendo con el lugar de origen. Son estudios que entienden que existe una sinergia entre los grupos emigrantes y los que han quedado en el lugar de origen, con objetivos y agendas comunes.

Para tratar de entender globalmente estos fenómenos, a partir de la década de los noventa se ha introducido el transnacionalismo como marco teórico y el concepto de diáspora como actor internacional.

Las ventajas del enfoque transnacional sobre el estudio de las migraciones es que este se entiende como un proceso articulado sobre varios ámbitos, como el social, el cultural, el económico y el político. Esto le imprime un carácter dinámico de cambio, tanto en la sociedad de acogida como en la de partida e, incluso, entre ambos; es decir, en el traslado mismo. Se rompe con la separación entre país receptor/emisor, convirtiéndolos en vasos comunicantes. Las comunidades de inmigrantes crean lazos “acá” y "allá”, constituyéndose en comunidades transnacionales o diásporas. El emigrante por sí mismo y a través de las instituciones que crea, vive simultáneamente en el país emisor y en el receptor. Esto cuestiona conceptos que hasta hace bien poco se entendían de una manera demasiado cerrada, como el de ciudadanía.

Por otro lado, estos grupos crean prácticas transnacionales propias que implican lo económico (como el envío de remesas o el favorecer las inversiones empresariales), lo cívico-social (participación en procesos de desarrollo comunitario), lo cultural (consumo de productos de origen, prácticas religiosas) y lo político, y que tienen objetivos tanto en origen como en destino. En definitiva, buscan mejorar la calidad de vida en todos estos aspectos.

En cuanto a lo político, es importante el lobbying y la incidencia en origen y en destino. Muchas veces lo que se busca es un objetivo puntual o a medio plazo, pero otras veces las diásporas actúan buscando grados de autonomía para la Madre Patria (incluso la soberanía completa). Esto es particularmente evidente en aquellos lugares con movimientos nacionalistas fuertes y aquí las diásporas se convierten en agentes de paradiplomacia. Esto implica la participación en los partidos políticos o la creación de partidos propios, en asociaciones o 
iglesias, redes informales de apoyo, ONG, etc. Con esto se logra una bidireccionalidad política, poco estudiada hasta ahora.

\section{¿Paradiplomacia de las diásporas?}

En los últimos años han aparecido nuevos actores en la arena internacional. Con el fenómeno de la globalización, los Estados nacionales han ido perdiendo cierto grado de poder o autonomía. Los movimientos de capital y las empresas transnacionales les han quitado parte de sus facultades para tomar decisiones económicas y lo mismo pasa a nivel cultural y político. De este modo se ven insertos en una tensión de fuerzas entre lo global y lo local. Esta presión les ha obligado a ceder parte de su soberanía, "hacia arriba", al delegarla en una estructura supranacional. Además, ha sucedido un fenómeno similar "hacia abajo", permitiendo la acción exterior de entidades subestatales. Cuando en esas regiones subestatales existe además una minoría nacional distinta a la general, que tiene su propia agenda de reivindicaciones, la situación se hace aún más compleja.

El modo más habitual de usar el concepto de paradiplomacia es el que utiliza Cornago Prieto, identificándolo con una mera "diplomacia paralela": "La participación de gobiernos no centrales en las relaciones internacionales a través del establecimiento de contactos ad hoc con entidades privadas o públicas del extranjero, con el fin de promover sus asuntos socioeconómicos y culturales, así como cualquier otra dimensión externa de sus competencias constitucionales” (Aldecoa \& Keating, 2000).

Sin embargo, consideramos que este término tiene un alcance limitado ya que encierra la idea de una diplomacia "paralela", que entra en conflicto con la "verdadera diplomacia" del Estado nacional. Por tanto, preferimos hacer referencia a la concepción de la "Diplomacia de múltiples niveles", en la que: "La diplomacia internacional no se considera como un proceso separado, regido por guardianes indiscutibles, sino como una red de interrelaciones con un reparto cambiante de actores que interactuarán de distintas maneras dependiendo 
del tema, de sus intereses en juego y de su capacidad para actuar en un medio político multinivel" (Hocking, como se cita en Aldecoa \& Keating, 2000, p. 50).

Esta perspectiva modifica directamente el concepto de diplomacia y le aporta el dinamismo propio que posee en la actualidad. Así mismo, evita concentrarse en las relaciones de conflicto y tensión para enmarcar también la concertación y la cooperación.

En cuanto al ámbito del Derecho Internacional Público, la postura clásica dice que estos Estados subnacionales no son sujetos de esta rama del derecho, porque generalmente se ha aceptado como único interlocutor válido al Estado nacional. Cabe destacar que las más modernas perspectivas, como la de Matthias Herdegen, asocian conceptualmente a los Estados confederados -o uniones constitucionales- y las Uniones o Asociaciones de Estados -o uniones de Derecho Internacional Público- vinculando la subjetividad jurídica internacional de estos acuerdos asociativos, sean internos o internacionales, bajo el mismo paraguas, para, a partir de tal caracterización, también admitir como sujetos -al menos parciales- a los Estados miembros (entes subnacionales) de un Estado Federal. Otros autores hablan de sujetos primarios (los Estado-nación) y secundarios o derivados, porque su condición deviene de este último ${ }^{1}$.

Otro elemento a tener en cuenta, y que suele frecuentar las investigaciones sobre la materia, es el peligro de la visión estatocéntrica. Las actividades externas de los gobiernos no centrales son generalmente enmarcadas dentro de la "baja política" (las cuestiones económicas), mientras que el Estado-nación domina la "alta política” (seguridad y defensa, por ejemplo). Esta distinción, si bien generalmente es cierta, tiende a implicar una menor relevancia de la "baja política" por sobre la "alta política".

Estas situaciones con regiones subnacionales que se largan a la arena internacional se exacerban cuando estas tienen su propia lengua y cultura, y una larga historia de reivindicaciones nacionalistas,

1 Aquí cabe distinguir al sujeto de Derecho Internacional Público, del actor de Política exterior o internacional, pudiendo estos encontrarse unidos o no en una misma entidad, persona u organización. 
y han aprendido a actuar en la esfera internacional para lograr su reconocimiento con un objetivo de máxima que es la obtención de su soberanía, o con objetivos menores, como son la adquisición de mayores niveles de autonomía. Muchas veces, como es en el caso de los irlandeses y vascos, se ha utilizado ampliamente a sus Diásporas para reforzar esta acción exterior. Nosotros entendemos que esta actividad se encuadra en el concepto de "paradiplomacia” de Ivo D. Duchacek. Este fenómeno tuvo su origen histórico después de la Segunda Guerra Mundial. La Creación de la Organización de Naciones Unidas significó la creación de la primera institución supranacional y la Carta de San Francisco la piedra angular de un nuevo derecho internacional. Aunque los Estados nación siguen siendo los protagonistas, han ido surgiendo otros actores secundarios, como son las ONG, partidos políticos, o las Diásporas.

Teóricamente esta situación generó recientemente debates nuevos donde se valora una nueva matriz de interacciones, con actores que son más habilidosos que los Estados, para manejar lo que Joseph Nye llama el Soft Power o poder suave (Nye, 2004). Es decir, el uso de lo ideológico y cultural como herramienta de influencia, más que la presión política, económica e incluso militar. Sin embargo, es necesario destacar que esta acción diplomática, que llevan a cabo estos actores secundarios - por llamarlos de alguna manera- es muy distinta a la tradicional de los Estados. Por un lado, es más experimental y basada en la prueba y el error, también se utiliza un fuerte involucramiento de la sociedad civil que, para el caso de las diásporas, es tanto el local de la sociedad de acogida como el de la Madre Patria.

Los movimientos nacionalistas no solo persiguen sus objetivos a través de la acción política interior, sino también a través de la proyección exterior que difunda la imagen de Nación sin Estado y de ese modo conseguir aliados. Esta actividad es una característica esencial de los nacionalismos periféricos, pero la forma, contenidos e intensidad es distinta en cada uno, según su cultura política y orientación 
ideológica. Su éxito tiene mucho que ver con el contexto interno e internacional ${ }^{2}$.

Por eso, y siguiendo a Nuñez Seixas $(2010)^{3}$, podemos decir que la inserción de los movimientos nacionalistas en el plano internacional lo procuran a través de tres vías, que son complementarias y no excluyentes:

1. El cultivo de la opinión pública favorable en terceros países, aprovechando la existencia desde 1918 de las primeras organizaciones internacionales de cooperación entre los Estados.

2. La búsqueda de un Estado protector extranjero, que por motivos altruistas o de estrategia propia, los apoyase frente al Estado opresor.

3. La colaboración con otros movimientos nacionalistas o minorías nacionales, intentando articular estrategias en común. Así, la acción exterior de los movimientos nacionalistas se convierte en un juego interactivo de imágenes y realidades, de mitos ideológicos y pragmatismo político.

Otro aspecto importante a tener en cuenta es que los nacionalismos subestatales muchas veces buscan sus objetivos usando de forma instrumental su diáspora; es decir, los grupos de emigrados que se han asentado en otros países. O, dicho de otro modo, la utilización de canales informales de negociación, los cuales son claves en política internacional. Estos grupos pueden tener una agenda propia distinta a la de sus "Madres Patrias" pero por lo general comparten objetivos y aportan dinero, hombres, armas, e incluso manejo de influencias.

2 Seguramente la creación del Estado de Israel se pueda decir que, a grandes rasgos, fue la exitosa conjunción de un movimiento Sionista activo y movilizado, una diáspora organizada y las trágicas consecuencias de la Shoá, al fin de la Segunda Guerra Mundial con los Aliados (en particular Inglaterra y Estados Unidos) como vencedores.

3 Véase también Conversi, D. (1993). "Domino Effect or International Developments? The Influences of International Events and Political Ideologies on Catalan and Basque Nationalism", West European Politics, 16/1, 1993, pp. 245-270. 
Ciertas coyunturas particulares permiten una movilización de las diásporas, sobre todo cuando se encuentran en situaciones de agresión o vulnerabilidad. La amenaza puede servir como una fuerza importante de movilización comunitaria, creando instituciones, recaudando fondos y ayudando militarmente. Esta ayuda militar ofrecida por una Diáspora, según Shain (1989), puede incluir la recaudación de fondos, en apoyo de las compras militares, el suministro directo de armas, o la organización de "una fuente de reclutas". Pero también puede hacerse movilizando a la opinión pública, a través de la propaganda. Llegado el momento, su participación será valiosa para gestionar la paz y descomprimir posibles conflictos, como los que provoca a veces la desmovilización de combatientes y la reinserción de los presos amnistiados.

\section{Inmigración irlandesa y vasca a la Argentina}

Desde la proclamación oficial de su independencia en 1816, la República Argentina se vio envuelta en una serie de luchas, tanto exteriores -para consolidar por completo la independencia de España- como interiores, tratando de resolver la cuestión de la organización definitiva del país. La llamada Generación del 80 fue la encargada de diseñar este nuevo Estado a partir de las premisas de un orden conservador en lo político y liberal en lo económico. En este sentido, será imperioso insertar al país dentro de la división internacional del trabajo como proveedor de materias primas (básicamente cereales y carnes), convirtiéndose en socio de Gran Bretaña. Para lograr este cometido era fundamental el incentivo a la inmigración.

Tanto vascos como irlandeses comparten en Argentina el ser grupos de inmigración temprana y minoritaria. Por otro lado, y en referencia al trabajo del historiador, son grupos difíciles de reconocer en los documentos oficiales, al figurar como ciudadanos españoles, franceses o ingleses. Esta circunstancia es la que ha obligado a 
los investigadores a tratar de identificarlos a partir del origen de sus apellidos, con todas las dificultades que esto implica.

La etapa abordada específicamente en este trabajo es el período comprendido entre 1862 y 1922. Tanto la fecha inicial como la final del periodo estudiado están relacionadas con el proceso histórico argentino. El 5 de octubre de 1862 fue elegido presidente de la República el General Bartolomé Mitre, comenzando de este modo las llamadas "Presidencias Históricas" que implicaron la reunificación del país a partir de una Constitución, el fin de las guerras civiles y el comienzo del modelo creado por la Generación del 80. 1922 fue el año de finalización del primer período presidencial del Dr. Hipólito Yrigoyen, el primer mandatario elegido con la Ley Sáenz Peña (1912) de voto secreto, universal y obligatorio. Además, al otro lado del Atlántico, ese año entró en vigor el tratado que crea el Estado Libre Irlandés y comenzó la Guerra Civil en la isla y en España se vivía la crisis del reinado de Alfonso XIII, dando lugar un año después a la dictadura de Primo de Rivera, que supuso un cambio importante en la estrategia del nacionalismo vasco, imposibilitado de actuar como lo había venido haciendo durante la Restauración alfonsina. Un año antes se había producido la escisión entre moderados y radicales, dentro del nacionalismo vasco, que en parte tiene relación con lo que sucede casi a la vez en Irlanda.

Las diásporas irlandesas y vascas no son muy diferentes en sus procesos migratorios, al ser dos movimientos tempranos, no ser numerosos y llegar a Argentina a través de cadenas migratorias. Sus procesos de asimilación son también similares, por lo exitosos, y por su ascenso social -unido al enriquecimiento al que llegaron ciertos sectores dentro de ellas-, debido a la ocupación agraria, primeramente lanar y luego vacuna. Sin embargo, sí hay algunas variables donde se marcan profundas diferencias entre las comunidades de vascos e irlandeses en Argentina, como el marco asociativo y su acción política (doméstica y externa).

Tanto irlandeses como vascos -lo mismo que el resto de la mayoría de colectividades extranjeras- buscaron agruparse, creando sus propias instituciones asociativas para apoyarse mutuamente, socorrerse en caso de necesidad y compartir y potenciar objetivos comunes. 
Para los irlandeses, la fuerte acción del clero les dio cierta estabilidad y homogeneidad. Incluso sectores no católicos o más pro-británicos participaban en las acciones asistenciales de la colectividad. Todo esto permitió que desde muy temprano se sentaran las bases de una comunidad fuertemente dirigida por la Iglesia y encuadrada por esta.

No fue este el caso de las asociaciones vascas, donde la diversidad de procedencia, más un comportamiento selectivo y exclusivo, llevó a la diversidad de instituciones. En primer lugar fue lo geográfico lo que obligó a la creación de varias instituciones. El Centro Vasco de Buenos Aires, al permitir solo socios provenientes de las tres provincias vascongadas, dejó a un lado a los vascos del norte del Bidasoa, que fundaron el Centro Vasco Francés, además de los navarros, agrupados en el Centro Navarro. A esto se le sumó después la diversidad política e ideológica que marcó el nacimiento del Centro Vasco de Rosario, de fuerte tónica nacionalista.

A diferencia de lo que pasaba con los centros irlandeses, el asociacionismo de los vascos era más bien excluyente. El vasco realmente era tomado con una visión muy limitada. Incluso debió pasar bastante tiempo para que los hijos de vascos nacidos en América tuvieran un rol de socios plenos. El caso de la creación del Euskal Echea, centro asistencial donde participan todos los sectores, era más una excepción que una regla y su constitución fue muy trabajosa.

Además, desde finales del siglo XIX existió un enfrentamiento entre "vascos" y "vascongados" (es decir, entre nacionalistas vascos y españoles o españolistas) en los centros vascos, que llevó a sucesivos cambios de directivas, deserciones de los miembros, disputas y regreso de socios. Estas diferencias se intensificaron con la llegada de grupos nacionalistas hacia 1910, y la activa participación de este nuevo sector abertzale. A diferencia del caso irlandés, estas discrepancias internas e ideológicas tan marcadas no permitieron el surgimiento de un único liderazgo fuerte, capaz de encolumnar a la Diáspora tras de sí. Las energías puestas en función de una búsqueda de identidad común llevaron a un nivel de actividad menor y a una dispersión de objetivos comunitarios.

El colectivo irlandés y el vasco sí tenían en común una fuerte religiosidad. Sin embargo, las características de las mismas y el papel 
del clero en ellas diferían. Para los irlandeses, la catolicidad formaba parte de su identidad nacional. Si siempre lo constituyó de forma embrionaria, con el tiempo fue tornándose ideológicamente más explícito, sumándolo al celtismo. La religión, ser católico, se transformó en elemento de resistencia contra el protestante invasor. El liderazgo, o mejor, la figura del líder (el sacerdote), se trasladaron con la inmigración.

Así mismo, también la mayoría de los vascos eran profundamente católicos y, por esto, el sacerdote tenía también un ascendente moral dentro de la colectividad. No obstante, hasta entrado el siglo XX, su papel en Argentina estará focalizado en la educación y asistencia espiritual del colectivo vasco, dejando a un lado una indoctrinación política. Esta solo se produjo cuando empezaron a llegar a Argentina algunos sacerdotes y religiosos vascos nacionalistas, a veces desplazados de España por sus superiores precisamente por cuestiones políticas. Hay que tener en cuenta que, a diferencia de lo que pasaba con Irlanda (donde el enemigo, Inglaterra, era no católico), el nacionalismo vasco se enfrentó con una España mayoritariamente católica y, en consecuencia, no pudo asumir la variable religiosa como elemento de diferenciación, incluso a pesar de la trascendencia que el catolicismo tradicionalista tuvo en su ideología.

De todas maneras, el clero vasco exiliado debía enfrentarse con una colectividad vasca más numerosa, dispersa y heterogénea que la irlandesa. Esto constituyó una de las diferencias fundamentales entre ambas diásporas. Aún siendo importante la incidencia política del clero en el caso vasco, el hecho de que hubiera sacerdotes, lo mismo que laicos, con distintas convicciones políticas, imposibilitaba su conversión en referentes nacionales únicos frente al otro protestante, tal y como sucedía en el caso irlandés.

En relación con la Paradiplomacia -entendida como la acción exterior de actores no-estatales- la diáspora irlandesa en Argentina fue eficaz a la hora de apoyar las luchas nacionalistas en Irlanda, incluso a pesar de la relación cuasi simbiótica de Argentina con Inglaterra. Esa relación entre la Diáspora y el nacionalismo irlandés se realizó a través del involucramiento político, la acción sobre la sociedad civil, el envío de fondos y el apoyo a la acción militar. 
Una vez más, el caso vasco aparece como muy diferente al irlandés. La Diáspora vasca se enfrentó con dificultades internas y con desavenencias, que no hacían más que reflejar el conflicto identitario existente en el País Vasco.

En cuanto a los contactos entre ambos grupos, Irlanda fue un espejo donde el nacionalismo vasco podía mirarse (por el éxito de su propuesta, por su religiosidad católica, etc.); sin embargo, los irlandeses apenas se preocuparon por el nacionalismo vasco. En Argentina, no existieron contactos fluidos entre las dos Diásporas a nivel institucional. Los pocos encuentros que tuvieron lugar entre dirigentes nacionalistas fueron iniciativa de los dirigentes irlandeses que llegaron al país, buscando apoyos de todo tipo.

En términos generales, la principal dificultad que debió padecer la diáspora irlandesa fueron los límites impuestos por la presencia altamente influyente de Inglaterra en el país que la colocaban en una situación intermedia entre lo que ocurría en los Dominios británicos por un lado y Estados Unidos por el otro. Para el caso vasco, fueron sus mismos problemas y divisiones internos de diversa clase lo que le quitaron eficacia.

En este sentido, nos planteábamos si era posible aplicar el concepto de paradiplomacia a las Diásporas irlandesa y vasca en Argentina de la etapa que estudiamos. La respuesta es positiva con respecto al caso irlandés y negativa con respecto al vasco. La Diáspora irlandesa sí se convirtió (en la medida de sus posibilidades, aunque estas fueran pocas, comparadas con la potente colectividad irlandesa a Estados Unidos) en un medio de presión, de apoyo político, moral y financiero para la causa nacional irlandesa. Por el contrario, el nacionalismo vasco no consiguió en este periodo que su diáspora se convirtiera en un agente paradiplomático. La causa de esta divergencia no estuvo tanto en la propia diáspora sino en las enormes diferencias existentes entre la historia del País Vasco, en relación con España, y la de Irlanda, en relación con Inglaterra, que se reflejó en la existencia de dos movimientos nacionalistas muy distintos entre sí. 


\section{Bibliografía}

Aldecoa, F. y Keating, M. (eds.) (2000). Paradiplomacia: las relaciones internacionales de las regiones, Madrid, Editorial Marcial Pons.

Álvarez, G. (ed.) (1996). Emigración y redes sociales de los vascos en América. Vitoria-Gasteiz, Universidad del País Vasco.

Casquete, J. (2007). “Agitando emociones”, Cuadernos Bakeaz, 81.

Cava Mesa, B.; Contreras, L. y Pérez, F. (1992). Sociedad «Laurak Bat» de Buenos Aires. Sociedad "Laurak Bat» de Buenos Aires. Vitoria-Gasteiz, Gobierno Vasco.

Conversi, D. (1993). “Domino Effect or International Developments? The Influences of International Events and Political Ideologies on Catalan and Basque Nationalism”, West European Politics, 16/1, pp. 245-270.

Cruset, M. (ed.) (2012). Migration and New International Actors. Cambridge, Cambridge Scholars Publishing.

De Pablo, S. (Ed.) (1195) Los Nacionalistas. Historia del nacionalismo vasco, 1876-1960. Vitoria-Gasteiz, Fundación Sancho el Sabio.

Devoto, F. (2009). Historia de la Inmigración en la Argentina, Buenos Aires, Ed. Sudamericana.

Ezkerro, M. (2003). Historia del Laurak Bat de Buenos Aires. Vitoria-Gasteiz, Gobierno Vasco.

Núñez Seixas, X. (2010). “Galegos e irlandeses na diáspora (1830-1950): elementos para unha comparanza”, Galicia 21: Journal of Contemporary Galician Studies, 1.

Nye, J. S. Jr. (2004). Power in the Global Information Age: From Realism to Globalization. Londres, Routledge.

Shain, Y. (1989). The Frontier of Loyalty: Political Exilies in the Age of the Nation-State. Middletown, Wesleyan University Press. 
